\title{
Andrés Bello en su Aventura Creadora
}

Reconstruir la vida externa de un escritor quizá sea cosa de erudición y de paciente análisis de los hechos que la configuran. Pero ningún biógrafo aspira, en principio, a quedarse en tales límites; busca, por el contrario, ahondar en todo ese contexto para derivar de él un sentido que implique tanto la vida profunda como la obra del autor estudiado. No todas las biografías literarias, sin embargo, tienen acceso a ese campo de verdaderas significaciones. No pocas veces se cree haber descubierto el punto de conjunción entre los dos planos, cuando, en verdad, sólo se ha dado una relación causalista - y por tanto empobrecedora- entre vida y obra. Es la ilusión de una falsa óptica. Pensar que, en estos casos, cuentan más las experiencias y aun los puros acontecimientos vitales del autor; que en una vida todo está dado de manera obvia; que la obra no es sino una transposición literal de aquélla, y no su proyección simbólica. No se requiere, pues tan sólo erudición y capacidad analítica; es todavía más imprescindible el don de una imaginación penetrante y la sagacidad, la sutileza de un espíritu dialéctico. Lo que es vida profunda en un escritor está en su obra, en lo que ella tiene de aventura tanto con el lenguaje como con la vida misma. Así, una tentativa biográfica, como toda tentativa crítica, debe partir de la obra creada, aunque, por supuesto, situando a ésta en el contexto de la estricta biografía y del marco histórico. Sólo de este modo, quizá, se pueda llegar a un análisis que sea también una visión realmente vivaz y totalizadora. Que sea una verdadera recreación. Pues de ello se trata.

Justamente, los estudios biográficos sobre Andrés Bello, hasta ahora, tal vez hayan padecido de algunas de estas fallas y limitaciones. Entre las más obvias: la ausencia de una relación dialéctica entre su vida y su creación intelectual (salvo estudios como los de Pedro Grases, Edoardo Crema, especialmente). También hay que señalar la falta de una perspectiva totalizadora. En lo esencial, esas fallas vienen a ser superadas por el nuevo libro de Emir Rodriguez Monegal: El otro Andrés Bello. ${ }^{1}$ Aunque

1 Caracas, Monte Avila Editores, 1969. 
el enfoque de este libro es parcial, ello tiene otro sentido. En efecto, su campo específico es el estudio de la vida y la obra de bello, pero dentro de una unidad dinámica. Al propio autor no se le escapa que la empresa intelectual de ello es tan vasta y $\tan$ múltiple que no puede ser abordada por un solo espiecialista. Para abarcarla en su totalidad, reconoce justamente, "hace falta una medida que esté forjada a su misma escala" ( $p$. 324). Es decir, se requeriría el enfoque de varios especialistas.

Pero si el libro de Rodríguez Monegal es parcial en este sentido, es lo más completo e integrador en su propio campo. No sólo un tenaz y, a veces, apasionante recorrido a través de la aventura vital de Bello; sobre todo la relación de esa aventura con la obra creadora y, más aún, la visión de esta última en su doble plano: la creación poética y la creación crítica. Incluso su perspectiva es todavía más amplia: el autor no olvida profundizar en el marco histórico en que se desarrolló la creación de Bello, lo que, en ciertos momentos de este libro, arroja nueva luz sobre textos fundamentales como "Alocución a la poesía" y como el Discurso inaugural en la Universidad de Chile. Libro parcial, pues, pero ya vemos que también central: en el tema que desarrolla se encuentra, ciertamente, como el mismo autor lo cree, "lo que es más original al tiempo que lo que es más comprometedoramente personal" de la obra de Bello (p. 450). De manera que si en la creación literaria está la clave de Bello, el análisis que se haga de ella es igualmente, en gran medida, el mejor punto de partida para captar el sentido total de su personalidad y de su labor intelectual. Y ésta es una de las virtudes sobresalientes del libro de Rodríguez Monegal: su capacidad para dar la significación total partiendo de lo parcial. Por ello se trata de algo más que de una biografía literaria; es sobre todo una biografía espiritual, desde ahora indispensable, por cierto, para comprender cualquiera de las faces de Bello. Lo que en él se revela no son tan sólo las estructuras esenciales de una obra literaria, así como el verdadero temple de un escritor que fue a la vez el primer humanista hispanoamericano, sino también, más profundamente, la dramática gestación de una y otro. Lo cual le restituye a Bello algo más que su valor ejemplar. Ese algo es quizá el verdadero hallazgo de este libro: la vitalidad, aún vigente, de un hombre para quien la, pasión intelectual era igualmente pasión de vida y de mundo. Por ello el humanismo del Bello que nos presenta Rodríguez Monegal sobresale del marco puramente académico en que se le había confinado erróneamente: se había desvirtuado lo que era rigor exigente y, por ello mismo, más vivo y necesario en el ámbito hispanoamericano. Ese rigor era también a su manera, una forma de la gran aventura creadora de Bello. "El primer 
aventurero hispanoamericano que asoma el Mundo Nuevo de la Europa romántica, el primer viajero nuestro en las tierras inéditas de la Revolución industrial, el primer cronista de la maravilla de una humanidad llena de sueños de progreso, de civilización, de grandeza", lo llama significativamente Rodríguez Monegal (p. 11).

Lo que nos propone, pues, este libro es otro Andrés Bello. Ello no implica que su autor pretenda dar un nuevo Bello, una suerte de imagen inédita que nadie antes hubiese vislumbrado. Con su honestidad y objetividad habituales, Rodríguez Monegal no sólo reconoce el aporte iluminador de otros especialistas, sino que los acoge y aun los destaca. Pero a la vez llega a integrar esos aportes en una visión más amplia y penetrante. Esta visión, por supuesto, debe mucho al laborioso estudio y a la erudición: el autor conoce todo lo esencial (y quizá aun lo inesencial) que se ha escrito sobre Bello; ha frecuentado las diversas ediciones de sus Obras completas; ha investigado también en fuentes tan importantes como la colección de periódicos chilenos en que Bello colaboró, y, claro está, tiene como pocos un conocimiento vivo de la literatura de la época, así como de su contexto histórico (tan visible sobre todo en su análisis del Romanticismo y en la recreación de la época londinense de Bello). Pero si ello da solidez, riqueza y dinamismo a su visión, no es lo que le comunica todo el vuelo y la profundidad que la caracteriza. Esto último surge, más bien, de una suette de empatía del autor con el destino de Bello en el plano vital y creador. Esa empatía es, por supuesto, producto de una identificación profunda con la persona de Bello, con lo que hay en ella de dimensión dramática, pero también ejemplar y aun actual en el mundo hispanoamericano. Esto nos parece esencial. Así, el autor no ve a Bello como un personaje distante, sino como criatura cercana, real, y quizá también en cierto modo imaginaria, mítica, íntimamente ligada a nuestro destino hispanoamericano. De ahí que el método de Rodríguez Monegal esté inteligentemente sugerido en la frase de Proust (¿no es ello una verdadera clave?) que pone de epígrafe a su libro: "Mais cette évolution d'une pensée, j'ai n'ai pas voulu l'analyser abstraitement mais la récréer, la faire vivre". Este método supone, en gran medida, una doble participación: afectiva e imaginaria; pero implica sobre todo la capacidad de hacer actual y vivo lo pasado, de hacernos sentir las proyecciones de éste aun en nuestra propia existencia, individual o colectiva. Así, el Bello de Rodríguez Monegal es otro porque ha sido despojado de las pesadas galas retóricas con que muchos eruditos lo habían afantasmado. El autor ha revelado su verdadera estirpe crea- 
dora, lo ha recreado en la letra viva de su obra y ha precisado en ésta la pasión vital que la nutre.

En otras palabras, Rodríguez Monegal ha sabido darnos un Bello más humano, es decir, más memorable. No porque haya hecho de su vida una aventura en cierto modo novelesca - capacidad que no es rara en el autor: ¿habría que recordar su libro sobre Horacio Quiroga? Quizá tampoco porque haya iluminado de manera eficaz - lo que ya, en sí mismo, es un rasgo notable de su libro- su obra poética y crítica, mostrando su larga evolución y señalando los valores que encierra, a veces realmente renovadores, especialmente en el campo de la investigación y de la crítica literarias. Sino, sobre todo, porque nos lo presenta como un escritor problemático. En efecto, todo en la vida o en la creación intelectual se le da a Bello como problema o como drama. Pero no fue un espíritu evasivo. Fue, por el contrario, un ser movido por una voluntad casi sobrehumana de creación y de realización. Esta voluntad es su norte y lo que le permite enfrentarse a los problemas y a los momentos críticos con sabiduría superior: no les opone la pura pasión, sino una fuerza más tenaz y profunda de hombre que de alguna manera se siente marcado por cierta grandeza. Espíritu contenido y no desbordado, hubo en él un secreto dramatismo, que supo trascender gracias a esa voluntad férrea. Este, me parece, es uno de los aspectos claves de la personalidad de Bello, que domina también su obra. Lo que Rodríguez Monegal ha sabido captar con agudeza y visible afecto. Pocas veces, sin embargo, se le había comprendido tan profundamente. Algunos lo habían confundido con una suerte de frialdad, cuando no con cierto oportunismo. Pero esa voluntad de realización, invulnerable a todo (al asedio del azar individual como al asedio del azar hispanoamericano), está muy lejos de ser lo uno o lo otro. Especialmente porque ella no se limita al puro destino personal de Bello; implica, por el contrario, un objetivo superior: la creación de una cultura realmente hispanoamericana. Bello asume este objetivo como su verdadera misión. Aunque no del todo explícito, es, creo, el tema central, y lo que le da unidad, del estudio de Rodríguez Monegal. A la luz de esta perspectiva es como logra desvirtuar muchos malentendidos y a la vez precisar los perfiles de algunos hechos históricos fundamentales.

En primer lugar, el tema de Bello y el Romanticismo, que el autor esclarece hasta en sus últimas implicaciones. Asume, sobre todo, no sólo una actitud de equilibrio; recurre especialmente para este tema a la elocuencia de los textos. Pocas veces se ha manejado de manera integral las fuentes al respecto. El autor no comparte, por supuesto, la idea de muchos 
críticos (Armando Donoso, Alberto Palcos, Ricardo Rojas) que ven en Bello la expresión última de la retórica neoclásica y, por tanto, el enemigo irreductible del romanticismo. Actitud comprensible en algunos contemporáneos de Bello que de algún modo se le opusieron (Mora, Sarmiento, Lastarria), Rodríguez Monegal demuestra su inexactitud esencial: ese Bello forma parte más de una leyenda que de la realidad. En efecto, Bello fue de los primeros hispanoamericanos en conocer el Romanticismo en una de sus fuentes más ricas: la literatura inglesa. Lo conoció y lo asimiló en su propia poesía (sus recreaciones de Víqtor Hugo, ciertos poemas de la madurez influidos por Byron, lo revelan); lo divulgó ya desde la época del "Repertorio Americano"; llegó incluso a formular una estética que se nutría de las ideas tománticas esenciales. ¿Por qué llegó a prosperar, sin embargo, la leyenda? En su época, porque Bello no se sumó incondicionalmente al nuevo movimiento; aun hizo críticas a algunos de sus excesos reales o posibles en el ámbito hispanoamericano. En nuestro tiempo, por ineptitud de cierta crítica que parece desconocer los textos mismos que Rodríguez Monegal rescata, o por inercia repetitiva, a veces interesada. Pero tampoco el autor se acoge a la tesis que, por reacción, cae en el otro extremo de presentarnos un Bello romántico. Su libro quiere evidenciar algo más significativo: la personalidad auténtica de Bello, su voluntad de crear una cultura hispanoamericana, su capacidad para reflexionar críticamente frente a la europea. Por ello nos dice: "Bello fue un neoclásico y fue un romántico $y$, sobre todo, fue algo más: fue él mismo" (p. 15). De ahí que al analizar la ya célebre polémica Sarmiento-Bello (más bien sus discípulos), el autor concluya: "A pesar de la fuerza contagiosa y del indudable atractivo de su exposición, Sarmiento cometía un error profundo: no comprendía que América necesitaba (necesita) el rigor y la exigencia, no la irresponsable tolerancia. Sarmiento, tan visionario en otros momentos y en otros temas, no levantaba entonces la vista del panorama chileno de 1842. Bello ya veía y proyectaba su visión sobre el instante presente hacia un futuro más fecundo" (p. 269). Así, lo importante en el libro de Rodríguez Monegal en torno al tema del Romanticismo es ver cómo Bello logró asimilar con lucidez y espíritu moderno las nuevas tendencias (estéticas y aun ideológicas) desde una actitud personal y teniendo en cuenta el objetivo que regía su propia búsqueda: la cultura hispanoamericana. En tal sentido, Bello actuó como un verdadero creador y como un pensador de primera línea. Si su poesía no logró alcanzar siempre gran estilo y profundidad, aunque hay en ella logros que se adelantan a la época, su pensamiento crítico y sus investigaciones de la literatura medieval (otro 
rasgo que lo acercaba al Romanticismo) se sitúan entre los aportes más renovadores de su tiempo en el ámbito hispánico.

Igual actitud asume Bello en su actuación en Chile. Censurarle su colaboración con la oligarquía conservadora y pretender definirlo, en consecuencia, como una suerte de reaccionario político y de espíritu cerrado a todo lo nuevo, es por lo menos demasiado simplista. Esa colaboración no comprometió ni el verdadero pensamiento de Bello, ni tampoco su acción real. En verdad, fue un gran renovador y en una escala que pocos intelectuales de su tiempo, y aun del nuestro, han podido alcanzar. Además, Bello no sólo fue el creador de la nación chilena en múltiples campos (la educación, la literatura, la historia, el periodismo, el orden juridico); fue también el gran propulsor de una idea continental. Los capítulos (más de la mitad del libro) que Rodríguez Monegal dedica a esta etapa de la vida de Bello corresponden en riqueza de datos, poder de evocación, capacidad de análisis histórico, cultural y psicológico, a la enorme labor que en estas décadas desarrolló el gran humanista, así como a la secreta intensidad de su propia existencia. Incluso llegan a desbordat los límites de su propio campo. Estos capítulos son una verdadera historia del pensamiento hispanoamericano de la época. Por ello El otro Andrés Bello ess algo más que la recreación de un destino individual; es también la visión apasionante de un momento esencial en nuestro desarrollo espiritual. Es la virtud de las biografías que saben comprender que una existencia puede encerrar todo un mundo.

University of Pittsburgh

GUILlERMO SUCRE 